\title{
FORMULASI SEDIAAN KRIM ANTI AGING BERBAHAN AKTIF EKSTRAK BUAH LIBO (FICUS VARIEGATA, BLUME)
}

\author{
Nor Yasin Al Amin ${ }^{1, \dagger}$, Nisa Naspiah ${ }^{1}$, Rolan Rusli ${ }^{1,2, \ddagger}$ \\ ${ }^{1}$ Laboratorium Penelitian dan Pengembangan Kefarmasian "Farmaka Tropis", \\ Fakultas Farmasi, Universitas Mulawarman, Samarinda, Indonesia \\ †Email: yasiny572@gmail.com \\ ${ }^{2}$ Kelompok Bidang Ilmu Kimia Farmasi, Fakultas Farmasi, \\ Universitas Mulawarman, Samarinda, Indonesia \\ *Email: rolan@farmasi.unmul.ac.id
}

\begin{abstract}
Libo fruit (F.variegata) is a natural ingredient that has the potential to protect the skin because of the antioxidant content contained in it. The development of dosage forms in the form of anti aging creams is needed to be used by the public. This study aims to determine the formula and concentration of libo fruit extract which can provide a good anti aging effect. Determination of anti aging effects was carried out in vitro using a UV-VIS spectrophotometer. The test results showed that creams with extract concentrations of $5 \%$ and $15 \%$ had anti aging activities, respectively at $73 \%$ and $47 \%$.
\end{abstract}

Keywords: Cream, FRAP, Anti Aging, Libo

\begin{abstract}
ABSTRAK
Buah libo (F.variegata) merupakan bahan alam yang berpotensi untuk melindungi kulit karena kandungan antioksidan yang terdapat didalamnya. Pengembangan bentuk sediaan dalam bentuk krim anti aging diperlukan agar dapat dimanfaatkan oleh masyarakat. Penelitian ini bertujuan untuk mengetahui formula dan konsentrasi ekstrak buah libo yang dapat memberikan efek anti aging yang baik. Penentuan efek anti aging dilakukan secara in vitro menggunakan spektrofotometer UV-VIS. Hasil uji menunjukkan bahwa krim dengan konsentrasi ekstrak 5\% dan 15\% memiliki aktivitas anti-aging, berturut-turut adalah sebesar $73 \%$ dan $47 \%$.
\end{abstract}

Kata Kunci: Krim, FRAP, Anti Aging, Libo

DOI: https://doi.org/10.25026/mpc.v8i1.337

\section{PENDAHULUAN}

Kulit sebagai organ terluar dan terluas merupakan pembatas dari lingkungan sekitar yang berfungsi untuk melindungi otot, ligamen, dan organ internal dari radiasi sinar ultraviolet (UV), dehidrasi, dan mikroorganisme. Fungsi perlindungan tersebut terjadi 
melalui sejumlah mekanisme biologis, seperti pembentukan lapisan tanduk secara terus menerus (keratinisasi dan pelepasan sel-sel yang sudah mati), respirasi dan pengaturan suhu tubuh, produksi sebum dan keringat, dan pembentukan pigmen melanin untuk melindungi kulit dari bahaya sinat ultraviolet matahari, sebagai peraba dan perasa, serta pertahanan terhadap tekanan infeksi dari luar [1-3].

Kulit bisa mengalami penuaan terutama pada daerah-daerah yang sering terpapar sinar matahari secara langsung seperti wajah, leher, bagian atas lengan, dan tangan. Lapisan kulit akan semakin menipis (sekitar $10 \%$ per 10 tahun), sehingga kulit akan semakin mudah mengalami iritasi dan rapuh. Jumlah produksi proteoglikan dan natural moisturizing factor (NMF) berkurang, sehingga kulit akan semakin kering. Jumlah pembuluh darah kulit juga berkurang dan terjadi perpanjangan pergantian sel kulit, sehingga kulit akan tampak kusam. Oleh karena itu, diperlukan suatu tambahan perlindungan bagi kulit yang salah satunya adalah kosmetik antiaging [4]. Kosmetik untuk antiaging sebagian besar bekerja dengan cara mencegah kerusakan akibat radiasi sinar UV atau memperbaiki kerusakan yang sudah terjadi. Antioksidan sering ditambahkan karena dapat mengurangi kerusakan oksidatif yang ditimbulkan oleh peningkatan reactive oxygen species (ROS) akibat radiasi UV [5].

Salah satu bahan alam yang bisa digunakan sebagai anti aging adalah buah libo ( $F$. varigeata). Buah libo memiliki aktivitas antioksidan yang sangat kuat [79], sehingga efektif melawan stress oksidatif di dalam mitokondria dan bertindak sebagai peredam hidroksi radikal.

Dalam memaksimalkan perawatan kulit melawan penuaan yang disebabkan oleh radikal bebas, perlu dilakukan formulasi ekstrak stroberi dalam sediaan krim. Sediaan krim yang diketahui dapat menyebar dengan mudah di kulit dan dapat menghantaran zat aktif dengan baik. Formulasi sediaan krim ditujukan agar krim dapat menyampaikan zat aktif dengan baik dan eksipien yang berada di dalam sediaan dapat mendukung penyampaiannya [4].

Penelitian ini bertujuan untuk memformulasikan sediaan krim anti aging yang berbahan aktif ekstrak buah libo serta mengetahui konsentrasi ekstrak buah libo yang memberikan efek anti aging yang baik.

\section{METODE PENELITIAN}

Buah Libo (Ficus variegata Blume.) yang tua dikumpulkan dan dibuat menjadi simplisia. Simplisia buah Libo dimaserasi dengan pelarut $n$ heksana. Kemudian filtrat disaring dan residu dimaserasi kembali dengan pelarut metanol selama 6 hari pada suhu kamar sambil sesekali diaduk dimana pergantian pelarut dilakukan setiap 2 hari sekali. Filtrat disaring dan dipekatkan dengan rotary evaporator sehingga diperoleh ekstrak kasar metanol $[9,10]$.

\section{Aktivitas Antioksidan Metode FRAP (Ferric Reducing Antioxidant Power)}

Uji aktivitas antioksidan

dilakukan untuk menentukan konsentrasi optimum ekstrak buah Libo ( $F$. variegata) yang beraktivitas sebagai anti aging yang digunakan dalam formulasi sediaan krim anti aging. Pengujian dilakukan dengan melarutkan $5 \mathrm{mg}$ ekstrak dalam etanol $96 \% 5 \mathrm{~mL}$, dicampurkan $1 \mathrm{~mL}$ dapar fosfat $0.2 \mathrm{M}$ dan $1 \mathrm{~mL} \quad \mathrm{~K}_{3} \mathrm{Fe}(\mathrm{CN})_{6}$, campuran diinkubasi selama 20 menit pada $50^{\circ} \mathrm{C}$. Setelah diinkubasi ditambahkan $1 \mathrm{~mL}$ TCA dan disentrifuge pada kecepatan $3000 \mathrm{rpm}$ selama 10 menit. $1 \mathrm{~mL}$ filtrat hasil sentrifugasi ditambahkan $1 \mathrm{~mL}$ akuades dan $0,5 \mathrm{~mL} \mathrm{FeCl}_{3}$, dan diukur absorbansinya menggunakan spektrofotometer UV-VIS pada panjang gelombang $400 \mathrm{~nm}$. Aktivitas antioksidan ditentukan dengan rumus: 


$$
\% \text { FRAP }=\frac{\text { Nilai FRAP Senyawa }}{\text { Nilai FRAP Fe }} \times 100 \%
$$

\section{Persiapan Formulasi}

Formula basis (Tabel 1) dimodifikasi dari Bernatoinene et al., 2011. Fase minyak (terdiri dari asam stearat, setil alkohol, mineral oil dan nipasol) dipanaskan di atas penangas air hingga suhu $70^{\circ} \mathrm{C}$ (hingga semua bahan melebur sempurna) kemudian diturunkan dari penangas air hingga suhu menjadi $60^{\circ} \mathrm{C}$ (hingga semua bahan melebur sempurna). Fase air (terdiri dari gliserin, nipagin, Tween 80, TEA, dan aquades) dipanaskan di atas penangas air hingga suhu $70^{\circ} \mathrm{C}$. Ekstrak kering dilarutkan terlebih dahulu dengan Tween 80 dan ditambahkan basis krim sedikit demi sedikit dan digerus hingga homogen.

Fase minyak dan air yang telah dibuat selanjutnya dicampurkan dengan cara menambahkan fase air ke dalam fase minyak secara perlahan sambil diaduk manual secara konstan dengan arah berlawanan arah jarum jam hingga suhu turun menjadi $35^{\circ} \mathrm{C}$.

Tabel 1. Formula Basis Krim

\begin{tabular}{cc}
\hline Bahan & Konsentrasi (\%) \\
\hline Asam Stearat & 7 \\
Cetyl alcohol & 2 \\
Mineral oil & 20 \\
Propil paraben & 0,05 \\
Glycerin & 10 \\
Metil Paraben & 0,05 \\
Tween 80 & 2 \\
TEA & 2 \\
Oleum Rosae & 0.005 \\
Aquades ad & 100 \\
\hline
\end{tabular}

\section{Evaluasi Sediaan Krim}

Menurut Sharon Nela, dkk 2013.

Evaluasi sediaan krim yang dilakukan meliputi pengamatan organoleptis, uji
$\mathrm{pH}$, uji viskositas, uji daya sebar, uji tipe emulsi, uji homogenitas.

\section{Pengujian Aktivitas Anti Aging}

Sampel krim sebanyak $0.3 \mathrm{~g}$ diekstraksi dengan $10 \mathrm{~mL}$ DMSO, kemudian disentrifugasi untuk memisahkan filtrat dengan basis krim. Filtrat ditampung untuk diuji aktivitasnya. Disiapkan larutan L-DOPA, dapar fosfat $6.5 \mathrm{M} \mathrm{pH} \mathrm{6.5,} \mathrm{larutan} \mathrm{tirosin,}$ larutan sampel dan 4 tabung reaksi. Bahan-bahan tersebut dicampurkan pada tabung yang sesuai kemudian diinkubasi pada suhu kamar $\left(27-30^{\circ} \mathrm{C}\right)$ selama 10 menit. Selanjutnya tirosinase ditambahkan ke dalam masing-masing tabung reaksi dan diinkubasi kembali selama 25 menit. Kemudian diukur serapannya dengan spektrofotometer UVVis pada panjang gelombang $475 \mathrm{~nm}$. Aktivitas antiaging ditentukan dengan rumus:

$\%$ Inhibisi Tirosinase $=\frac{\mathrm{A}-\mathrm{B}}{\mathrm{A}} \times 100 \%$

$\mathrm{A}=$ Absorbansi larutan tanpa sampel

$\mathrm{B}=$ Absorbansi larutan dengan penambahan sampel

\section{HASIL DAN PEMBAHASAN}

Libo merupakan salah satu tumbuhan yang merupakan sumber antioksidan yang potensial [8], karena memiliki kandungan metabolit sekunder seperti fenol, flavonoid, alkaloid dan steroid atau triterpenoid [7]. Senyawasenyawa bahan alam yang memiiki aktivitas antioksidan biasanya bertanggung jawab untuk melindungi tanaman dari pengaruh sinar buruk sinar UV [6].

Hasil uji aktivitas antioksidan
metode FRAP (Ferric Reduction Antioxidant Power) pada ekstrak buah libo dapat dilihat pada gambar 1 . 


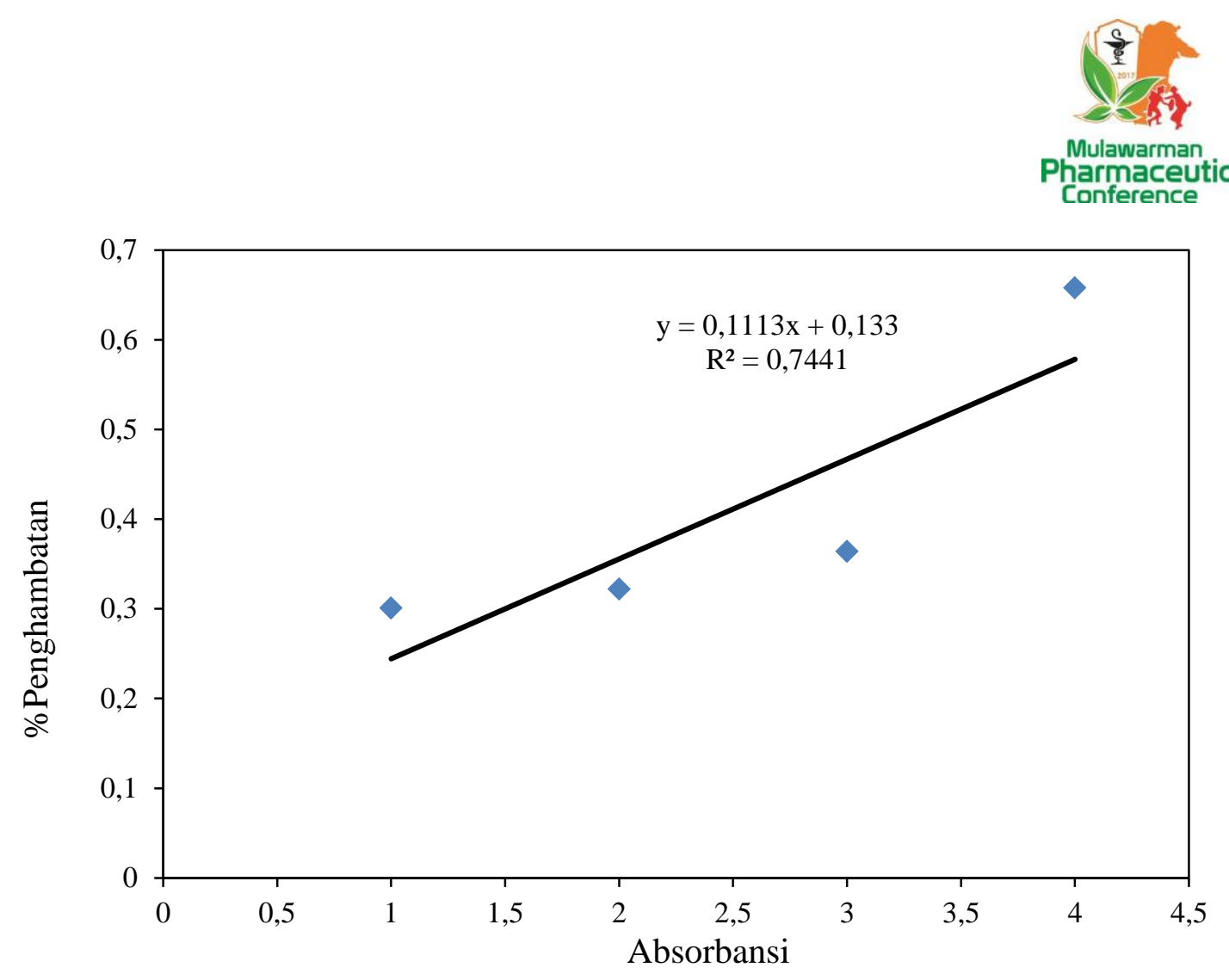

Gambar 1. Absorbansi Aktivitas Antioksidan Ekstrak Buah Libo

Beberapa metode telah dikembangkan untuk mengukur aktivitas antioksidan suatu sampel. Pada penelitian ini aktivitas antioksidan diukur melalui uji FRAP. Uji FRAP ini dipilih karena prosedurnya yang sederhana, metodenya murah, cepat dan reagen yang digunakan cukup sederhana serta tidak menggunakan alat khusus untuk menghitung total antioksidan. Penambahan TCA bertujuan agar kompleks kalium ferrosianida mengendap. Penambahan $\mathrm{FeCl}_{3}$ juga bertujuan untuk membentuk kompleks berwarna hijau sampai biru (biru berlin). Daya reduksi merupakan indikator potensi suatu senyawa antioksidan. Daya reduksi dalam hal ini diukur dari kemampuan suatu antioksidan untuk mengubah $\mathrm{Fe}^{3+}$ menjadi $\mathrm{Fe}^{2+}$. Pada tabel 2 menunjukkan adanya peningkatan aktivitas antioksidan, hal ini terjadi karena pada metode FRAP hasil yang didapatkan berbanding lurus dengan jumlah sampel yang digunakan, artinya semakin besar konsentrasi sampel yang digunakan maka semakin besar pula aktivitas antioksidan yang dihasilkan.

Tabel 2. Hasil Pengukuran Aktivitas Antioksidan Metode FRAP Ekstrak Buah Libo

\begin{tabular}{cc}
\hline Konsentrasi (\%) & $\begin{array}{c}\text { Aktivitas } \\
\text { Antioksidan (\%) }\end{array}$ \\
\hline 5 & 45 \\
10 & 48 \\
15 & 55 \\
\hline
\end{tabular}

\section{Hasil Formulasi Sediaan}

Krim dibuat dengan menggunakan ekstrak buah libo sebagai zat aktif dan beberapa eksipien sesuai dengan formula yang telah ditentukan. Sediaan krim yang telah dibuat dievaluasi dengan uji organoleptis, uji homogenitas, uji $\mathrm{pH}$, uji daya sebar, uji viskositas, dan uji stabilitas. 


\section{Uji Organoleptis}

Uji organoleptis yang dilakukan meliputi pemeriksaan bentuk, tekstur, warna, dan bau yang dilakukan secara visual. Hasil yang didapatkan adalah krim memiliki warna hijau yang dihasilkan dari warna ekstrak buah libo, memiliki konsistensi krim serta memiliki aroma mawar.

\section{Uji Homogenitas}

Hasil uji homogenitas fisik yang dilakukan pada awal pembuatan dan minggu terakhir pengamatan, menunjukkan bahwa basis dan krim tetap homogen. Hasil uji freeze and thaw menunjukkan pada masing-masing siklus baik formula basis dan krim antioksidan memiliki konsistensi krim sama seperti kontrol yang berarti bahwa tidak terjadi pemisahan fase.

\section{Uji pH}

Uji pH dilakukan pada awal pembuatan dan selama 30 hari masa penyimpanan. Data hasil pengukuran $\mathrm{pH}$ dapat dilihat pada tabel 3. Rentang $\mathrm{pH}$ normal kulit adalah 4,5- 6,8 (Lambers $\mathrm{H}$ et al., 2006) sehingga nilai $\mathrm{pH}$ basis dan krim antioksidan masih masuk dalam rentang $\mathrm{pH}$ normal kulit. Sehingga dapat disimpulkan bahwa $\mathrm{pH}$ basis dan krim stabil selama 30 hari.

\section{Uji Daya Sebar}

Uji daya sebar tidak memiliki nilai standar, melainkan relatif terhadap formula pembandingnya. Penilaian uji daya sebar ini untuk menggambarkan kemudahan krim ketika diaplikasikan pada kulit, semakin mudah diratakan pada kulit berarti akan memperluas area kulit yang kontak dengan krim yang berarti kemungkinan zat aktif untuk diabsorbsi akan makin besar.

\section{Uji Viskositas}

Viskositas basis krim perlu diperhatikan karena berkaitan dengan kenyamaan penggunaan. Krim harus mudah dioleskan dan dapat menempel pada kulit. Pengujian viskositas basis krim bertujuan untuk mengetahui viskositas (kekentalan) krim, viskositas standar sediaan krim yaitu 2-50 Pa.s. Nilai viskositas basis dan krim terjadi perubahan selama masa penyimpanan 30 hari, namun nilainya masih sesuai dengan persyaratan viskositas krim (Tabel 4).

Tabel 3. Uji pH Sediaan Krim

\begin{tabular}{ccccc}
\hline Formula & \multicolumn{4}{c}{$\mathrm{pH}$ Hari ke } \\
\cline { 2 - 5 } & 0 & 10 & 20 & 30 \\
\hline Fc & 6.5 & 6.5 & 6.5 & 6.5 \\
F1 & 6.83 & 6.80 & 6.80 & 6.80 \\
F2 & 6.81 & 6.78 & 6.78 & 6.78 \\
F3 & 6.753 & 6.73 & 6.73 & 6.73 \\
\hline
\end{tabular}

Tabel 4. Uji Viskositas Sediaan Krim

\begin{tabular}{ccccc}
\hline Formula & \multicolumn{4}{c}{ Viskositas (Pa.s) Hari ke } \\
\cline { 2 - 5 } & 0 & 10 & 20 & 30 \\
\hline Fc & 3.635 & 3.386 & 3.247 & 3.184 \\
F1 & 3.133 & 4.642 & 3.724 & 3.030 \\
F2 & 2.216 & 3.408 & 3.139 & 2.893 \\
F3 & 2.853 & 3.360 & 3.016 & 2.784 \\
\hline
\end{tabular}


Tabel 5. Uji Aktivitas Krim Anti Aging

\begin{tabular}{ccc}
\hline Formula & Konsentrasi & \%Penghambatan \\
\hline F1 & $5 \%$ & $73 \%$ \\
F2 & $10 \%$ & $25 \%$ \\
F3 & $15 \%$ & $47 \%$ \\
\hline
\end{tabular}

\section{Uji Stabilitas}

pada krim pengamatan organoleptis penyimpanan dalam suhu dingin $\left(4^{\circ} \mathrm{C}\right)$, suhu ruang $\left(25^{\circ} \mathrm{C}\right)$, dan suhu tinggi $\left(40^{\circ} \mathrm{C}\right)$. Krim pada penyimpanan tiga suhu yang berbeda tersebut dari hari ke 0 hingga hari ke 30 tidak terlihat adanya pemisahan fase minyak dan fase air.

Masing-masing krim mengalami perubahan warna menjadi lebih pudar pada $4^{\circ} \mathrm{C}$ dan $40^{\circ} \mathrm{C}$, sedangkan pada penyimpanan suhu ruang tidak mengalami perubahan warna. Sediaan krim yang diuji dengan siklus freeze and thaw dengan suhu $4^{\circ} \mathrm{C}$ dan suhu $40^{\circ} \mathrm{C}$ selama 6 siklus menunjukkan tidak terjadi pemisahan fase. Dengan demikian dapat disimpulkan bahwa sediaan memiliki stabilitas yang baik.

\section{Aktivitas Anti Aging}

Pengujian aktivitas anti aging dilakukan dengan metode dopakrom. Dopakrom merupakan hasil oksidasi LDopa oleh tirosinase. Pembentukan dopakrom ini yang akan diukur dengan spektrofotometri UV-VIS pada panjang gelombang $400 \mathrm{~nm}$. Berdasarkan hasil pengukuran aktivitas krim anti aging yang berbahan aktif ekstrak buah libo dengan konsentrasi 5\%, 10\%, dan 15\% diperoleh $\%$ penghambatan tirosinase pada tabel 5.

Berdasarkan hasil tabel 5, sediaan krim yang memiliki konsentrasi berbeda, memiliki aktivitas penghambatan tirosinase yang berbeda pula. Tirosinase berperan penting pada pembentukan melanin. Jumlah melanin yang berlebih pada kulit dapat menyebakan hiperpigmentasi yang merupakan gejala penuaan dini. Pada krim dengan konsentrasi $5 \%$ memiliki aktivitas penghambatan sebesar $73 \%$, sehingga dapat disimpulkan bahwa krim dengan konsentrasi $5 \%$ dapat digunakan sebagai krim anti aging yang dapat mencegah atau mengobati gejala penuaan dini yang disebabkan oleh radiasi sinar UV matahari.

\section{KESIMPULAN}

Krim berbahan aktif ekstrak buah libo ( $F$. variegata) memiliki aktivitas antiaging secara in vitro. Krim dengan konsentrasi ekstrak 5\% memiliki aktivitas yang baik dengan nilai $73 \%$. Sediaan krim memiliki stabilitas yang baik selama masa penyimpanan 30 hari.

\section{DAFTAR PUSTAKA}

1 Bal S, Ding Z, Elly V, Jiskoot W, Bouwstra J. Advances in transcutaneous vaccine delivery: Do all always lead to Rome? JCR 2010;148:266-82.

2 Fox L, Gerber M, Plessis J, Hamman J. Transderma drug delivery enhancement by compounds of natural origin. Molecules 2011;16:10507-40.

3 Basler, K., Bergmann, S., Heisig, M., Naegel, A., Zom-Kruppa, $\mathrm{M}$ and Brandner, J.M., The role of tight junction in skin barrier function and dermal absorption. JCR 2016;242:10518.

4 Lephart, E.D. Skin aging and oxidative stress: Equol's anti-aging effects via biochemichal and molecular mechanisms. Ageing Research Reviews 2016:31: 36-54. 
5 McDaniel DH, Nuadecker BA, DiNardo JC, Lewis JA, Maibach HI. Clinical efficacy assessment in photodamaged skin of $0,5 \%$ and $1,0 \%$ Indeboneno. JCD 2005;4:167-73.

6 Amrillah, M. S., Rusli, R., Fadraersada, J., 2015. Aktivitas Tabir Surya daun Miana (Coleus atropurpureus L. Benth). Jurnal Sains dan Kesehatan. 1 (4). 168-174. DOI: https://doi.org/10.25026/jsk.v1i4.35

7 Rusli, R., Hardina, M. P., Muflihah, F., Rahmadani, A., 2015. Profil Kromatografi Senyawa Aktif Antioksidan dan Antibakteri Fraksi nHeksana Dan Libo (Ficus variegata Blume.) Journal Tropical Pharmaceutical Chemistry. 3 (2). 124130.

DOI: https://doi.org/10.25026/jtpc.v3i2.98

8 Rijai, L. 2013. Potensi Tumbuhan Libo (Ficus variegata Blume) Sebagai Sumber Bahan Farmasi Potensial. Journal Tropical Pharmaceutical Chemistry. 2. (3). 166-179. DOI: https://doi.org/10.25026/itpc.v2i3.63

9 Ningsih, B. A., Rahmadani, A., Fadraersada, J., \& Rusli, R. (2016). Aktivitas Antibakteri dan Antioksidan
Isolat Fraksi Etil Asetat Buah Libo (Ficus variegata Blume.). Proceeding of Mulawarman Pharmaceuticals Conferences, 3(2), 114-120. https://doi.org/10.25026/mpc.v3i2.95

10 R Rusli, BA Ningsih, A Rahmadani, L Febrina, V Maulidya, J Fadraersada. Isolation and Antioxidant and Antibacterial Activity of Flavonoid from Ficus variegate Blume. Indonesian Journal of Chemistry (Accepted)

11 Bernatoniene, J., Masteikova, R., 2. Davalgiene, J., Peciura, R., Gauryliene, R., Bernatoniene, R. (2011). Topical Apllication Of Calendula officinalis (L.) ; Formulation and Evaluation of Hydrophilic With Antioxidant Activity. Journal of Medicinal Plants Research, 5(6), 868-877

12 Sharon, Nela. Anam, Syariful. Yuliet. 2013. Formulasi Krim Antioksidan Ekstrak Etanol Bawang Hutan (Eleutherine palmifolia L. Merr). Online Jurnal of Natural Science, Vol 2 (3) :111-122 